\title{
Lymph Node Involvement and Surgical Approach in Parathyroid Cancer
}

\author{
Klaus-Martin Schulte $\cdot$ Nadia Talat • \\ John Miell $\cdot$ Caje Moniz $\cdot$ Prakash Sinha . \\ Salvador Diaz-Cano
}

Published online: 17 July 2010

(C) Société Internationale de Chirurgie 2010

\begin{abstract}
Background The best surgical approach to parathyroid cancer is disputed. Recommendations vary and are built on incoherent evidence. High rates of recurrence and death require an in-depth review of underlying findings.

Methods This retrospective study includes 11 patients with parathyroid cancer who underwent surgery with central and/or lateral neck dissection by a single surgeon between 2005 and 2010. The diagnosis was based on histopathological criteria in all patients. Patterns of lymph node and soft tissue involvement of these and formerly reported patients were analysed based on full-text review of all published cases of parathyroid cancer.

Results In this series only 1 of 11 patients $(9.1 \%)$ manifested lymph node metastasis. In the literature, lymph node metastases have been reported in only $6.5 \%$ of 972 published patients, or in $32.1 \%$ of the 196 in whom lymph
\end{abstract}

K.-M. Schulte $(\bowtie) \cdot$ N. Talat

Department of Endocrine Surgery, King's College Hospital,

King's Health Partners, Denmark Hill, London SE5 9RS, UK

e-mail: klaus-martin.schulte@nhs.net

C. Moniz

Department of Clinical Chemistry, King's College Hospital,

King's Health Partners, London SE5 9RS, UK

S. Diaz-Cano

Department of Pathology, King's College Hospital,

King's Health Partners, London SE5 9RS, UK

J. Miell

Department of Endocrinology, University Hospital Lewisham, Lewisham, London SE13 6HL, UK

P. Sinha

Department of Surgery, Princess Royal University Hospital Bromley, Orpington, Kent BR6 8ND, UK node involvement was assessed by the authors. They were, with few exceptions, localised in the central compartment. Recurrence in soft tissue is more frequent than in locoregional lymph nodes.

Conclusion Oncological en bloc clearance of the central compartment with meticulous removal of all possibly involved soft tissues, including a systematic central lymph node resection, may improve outcomes and should be included in the routine approach to the suspicious parathyroid lesion. There is no need for a prophylactic lateral neck dissection.

$\begin{array}{ll}\text { Abbreviations } \\ \text { PTH } & \text { Parathyroid hormone } \\ \mathrm{Ca} & \text { Corrected serum calcium } \\ \mathrm{mM} / \mathrm{L} & \text { Millimoles per litre } \\ \mathrm{CI} & \text { Confidence interval } \\ \mathrm{RR} & \text { Relative risk } \\ \mathrm{OR} & \text { Odds ratio } \\ \mathrm{TNM} & \text { Tumour node metastasis }\end{array}$

\section{Introduction}

Parathyroid cancer is the cause of primary hyperparathyroidism in less than $3 \%$ of patients. Not only patient-related factors such as gender and age, but also biological features of the cancer and management of it have an impact on midterm and long-term survival [1]. There is ample evidence that complete surgical excision is the gold standard of therapy and that failure to perform radical surgery predisposes patients to a multifold increased risk of recurrence and death [1]. The presence of lymph node metastases is a 
strong adverse predictive factor [1]. A surgical approach by local excision only, as opposed to en bloc resection or resection including a systematic lymphadenectomy, equally confers a significantly higher risk of local recurrence and death [1]. Understandably, there are no data elucidating the predictive value of imaging to assess lymph node involvement in parathyroid cancer. Based on the current uncertainty of the extent of lymph node involvement and the effects of systematic lymph node resection on outcome, there is little consensus on the surgical approach. Reviews give varying advice and fall into five categories: advice for en bloc tumour resection but no explicit advice for lymphadenectomy [2-4], advice for en bloc resection with systematic central lymphadenectomy [5-13], advice for systematic central and lateral lymphadenectomy [5], advice for an indication for lateral lymphadenectomy based on specific findings only [6, 13-18], and explicit caution against prophylactic lateral lymph node dissection $[7,8$, 19-21]. The remarkable variation of opinion and review of the underlying evidence for such advice indicate a relative paucity of data. The localisation and origin of recurrent parathyroid cancer has not been elucidated sufficiently and evidence on the role of central and lateral lymph nodes as the site for origin of recurrence is poorly investigated. This case series and review aims to address this issue.

\section{Patients and methods}

The study format is that of a retrospective observational study in a single tertiary referral centre. Patients underwent surgery by the first author (KMS) between 2005 and 2009. Most patients' cases preoperatively underwent discussion by the endocrine multidisciplinary team, consisting of senior endocrinologists, pathologist, radiologist, nuclear medicine physician, biochemist, endocrine surgeon, and nursing staff. For 9 of 11 patients we held a preoperative suspicion of parathyroid cancer based on excessive calcium or PTH levels, ultrasound findings, a palpable lesion, and genetic background. In additional patients the intraoperative palpation raised suspicions; one patient had been operated on elsewhere and did not undergo primary lymph node resection.

The histopathological diagnosis of parathyroid cancer was confirmed by assessment of the original tumour blocks and slides by a single expert pathologist (SDC). For identification patients were numbered from 1 to 11 (Table 1). The diagnosis of parathyroid cancer required demonstrative evidence of invasion (i.e., infiltrative growth in the absence of prior neck intervention) and identification of vascular invasion or proof of lymph node or distant metastases, or the presence of capsular invasion with proof of either lymph node or distant metastases (Table 2). Broad

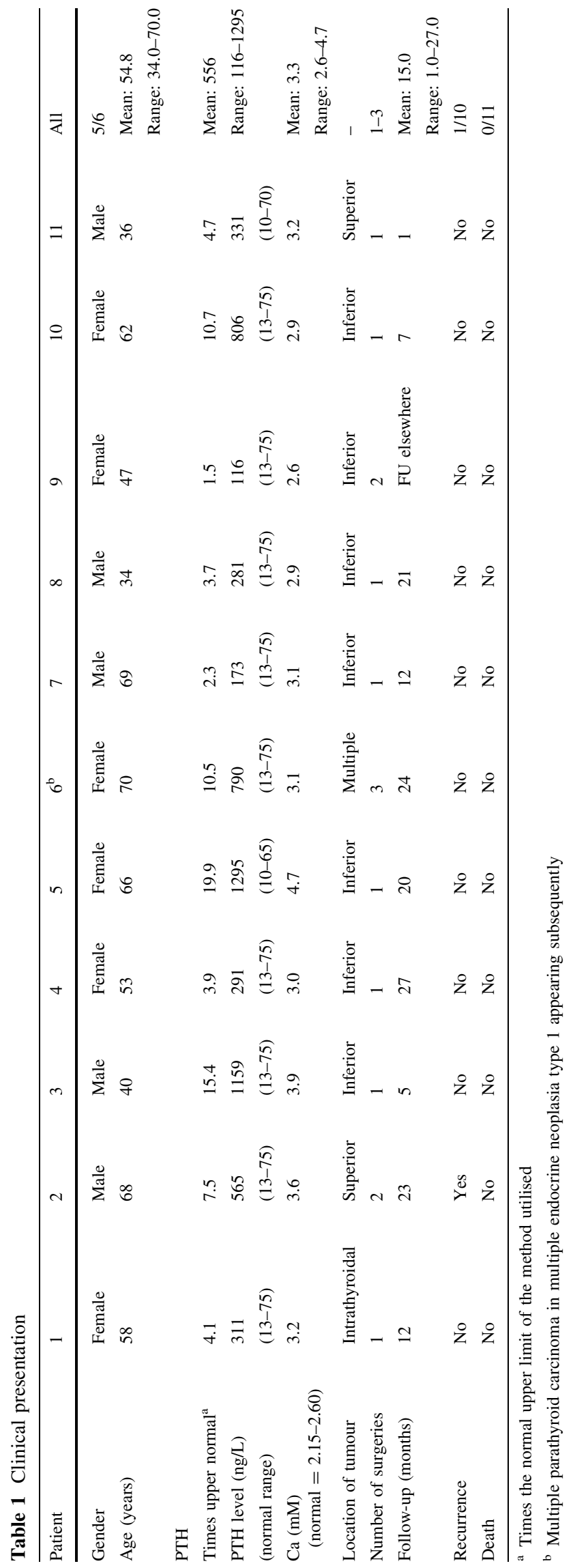




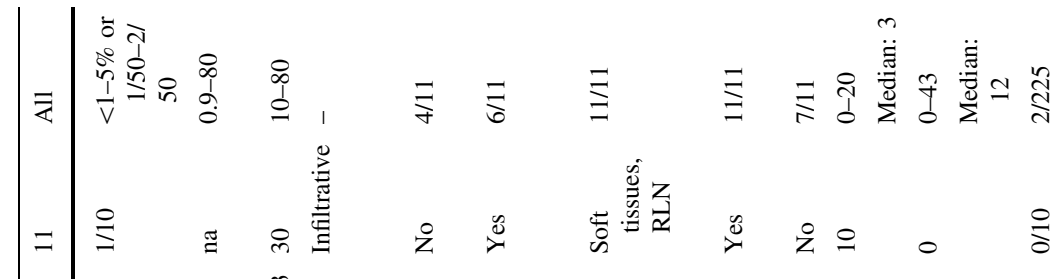

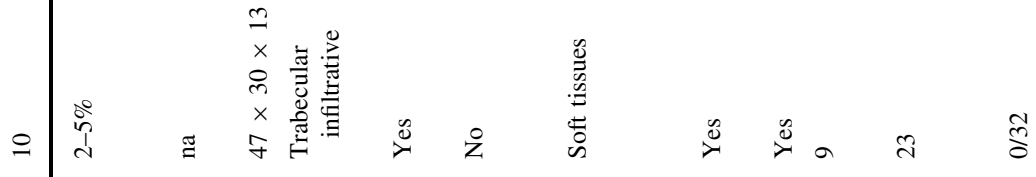

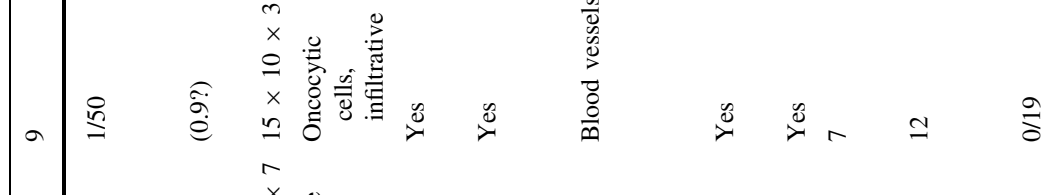

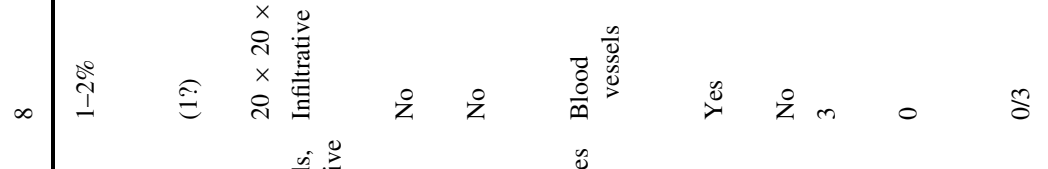

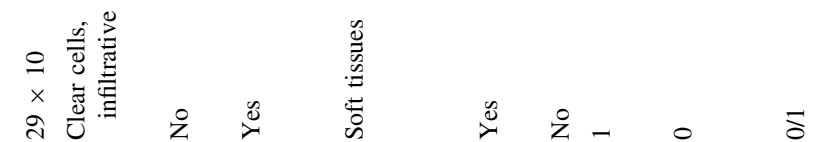

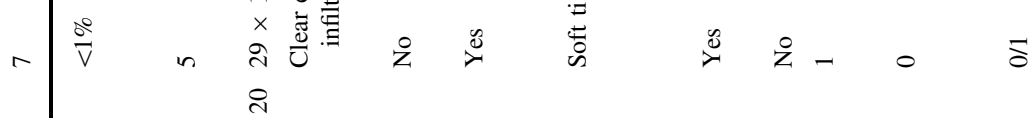

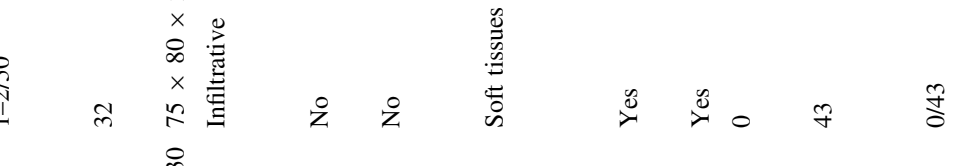

10

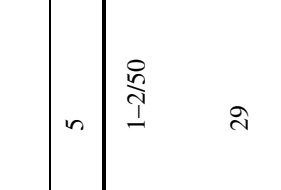

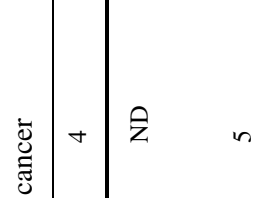

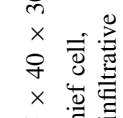

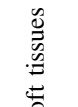

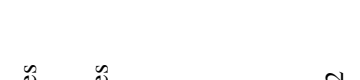

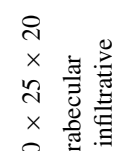

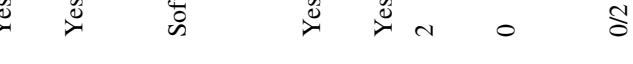

竞

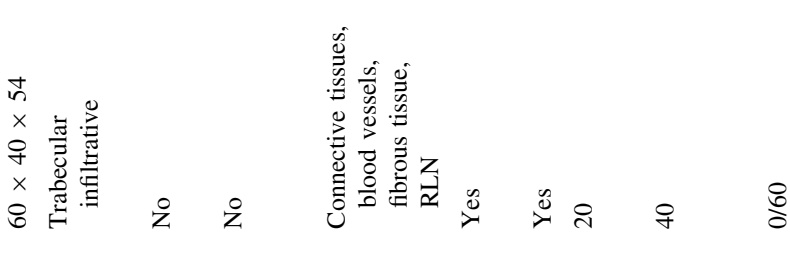

(2) 2

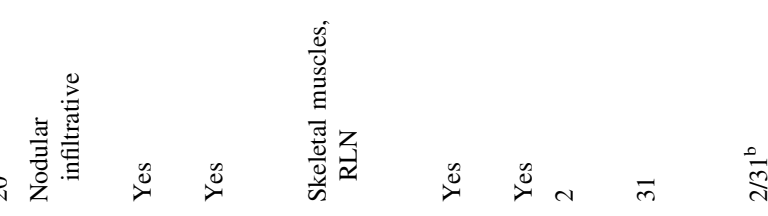

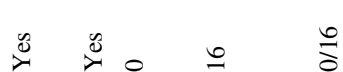

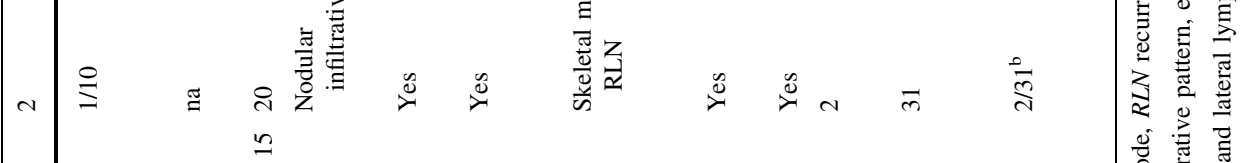

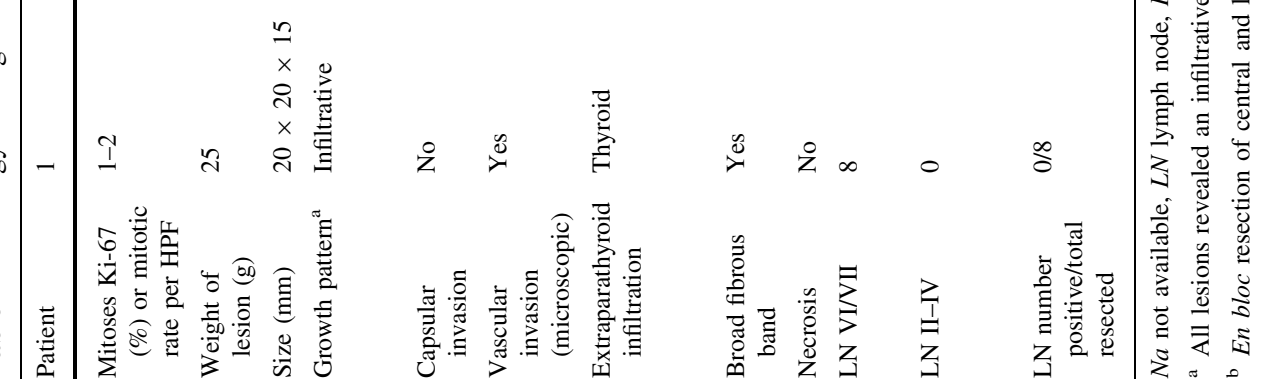


bands were considered a supporting element but not sufficient in their own right to establish diagnosis. In addition, specimens needed to meet microscopic criteria underpinning the diagnosis, including cellular features such as polygonal cell shape (case 2) granular cytoplasm (cases 2 and 4), and thick cytoplasmic membranes (case 2). Nuclear characteristics included enlargement (case 8), pleomorphism (cases 1,2, and 7), irregular chromatin distribution (cases 1, 3, and 6), and prominent nucleoli (cases 1 and 8). Mitotic counts, focal haemorrhage and necrosis, and apoptosis were used as additional indicators (Table 2). PTH and chromogranin immunostaining was used to ascertain the endocrine parathyroid nature of the lesions.

In order to identify previously reported patients with any form of lymph node resection, the NIH database PubMed (http://www.ncbi.nlm.nih.gov/sites/entrez) was searched using the search term "parathyroid cancer surgery" in February 2009. The search identified 4,754 articles. After reviewing the title, abstract, and keywords of each article, 450 cases of parathyroid cancer were identified in 156 articles published between 1961 and February 2009. Presentation of individual data in case reports and small case series was identified for 410 patients. Clustered data were available for 562 patients. We excluded patients with nonfunctional parathyroid cancer and secondary hyperparathyroidism and studies that did not meet our inclusion criteria of providing the following minimal information: (1) unequivocal evidence of parathyroid cancer in the form of either a histology description demonstrating vascular invasion or proof of lymph node or distant metastases and capsular invasion with proof of either lymph node or distant metastases (capsular invasion alone was not considered reliable unequivocal evidence for parathyroid cancer); (2) description of surgery for parathyroid cancer; (3) a description of the method of lymphadenectomy; and (4) confirmation of pathological results of the resected lymph nodes. Based on these criteria we included 55 studies [3, 5, $6,14,17-67]$. We carefully checked that patients were not subject of duplicate publication, have excluded data on duplicate patients, and have identified the related studies in detail [1].

A consistent terminology to describe the surgical approach was not used throughout the literature. We have categorised the surgical approaches used into the following categories: local excision (LE), a procedure in which the lesion is dissected following the margin of the peritumoural capsule; en bloc resection, any resection that includes surrounding soft tissues or/and the adjacent hemithyroid; radical resection, any form of en bloc resection that involves hypopharynx, oesophagus, larynx, trachea, recurrent laryngeal nerve, carotid artery, or jugular vein. Lymph node dissection was classified as central lymph node dissection corresponding to level VI of the classification scheme [68] or lateral neck dissection corresponding to the jugular.

Where data sets are incomplete we have indicated the exact numbers of patients for whom information was available and who were hence included in the calculation. We have abstained from multivariate regression analysis because of the inherent difficulties of incomplete data sets underlying this analysis.

\section{Results}

The study included 11 patients with histologically confirmed parathyroid cancer (Tables 1 and 2). Follow-up ranged between 1 and 27 months with a median of 20 months. Data on previously reported patients were available for 972 patients (Table 3). A literature review of these 972 patients with respect to soft tissue and lymph node involvement found during the initial presentation with later recurrence is presented in Table 4.

\section{Surgery}

All patients $(n=11)$ described in our series underwent surgical procedures. Resection of the recurrent laryngeal nerve was performed in three patients $(2,3$, and 11) because of circumferential encasement of the nerve. One patient (9) had undergone prior excision of the parathyroid cancer elsewhere and was referred for completion surgery soon after the initial surgery. We performed an ipsilateral hemithyroidectomy and en bloc resection of the tumour bed and central lymph node compartment.

In one patient (2) the lymph node resection of central and lateral compartments was done in one continuous block because there was a large inflammatory lesion of $7 \mathrm{~cm}$ extending from the oesophagus directly into the central and lateral compartments at levels II and III (Robbins classification) [68]. Two lymph node metastases were observed in this patient. They were in the vicinity of the parathyroid cancer. One lymph node was outside of the inflammatory mass, dorsal to the hypopharynx. The cancer measured only $20 \mathrm{~mm}$ and was directly infiltrating the oesophageal wall/low hypopharynx. The metastases were classified as level VI or central compartment metastases. The resection site of the hypopharynx was reconstructed by direct sutures; the proximal oesophagus was locally reconstructed after mobilisation.

Lymph node resection yielded positive nodes in only 1 of 11 patients $(9.1 \%)$ with histologically clear-cut parathyroid cancer. The total number of lymph nodes retrieved from the central compartment was significantly lower than that observed in thyroid cancer surgery cases performed by the same surgeon. One reason may be that these parathyroid 


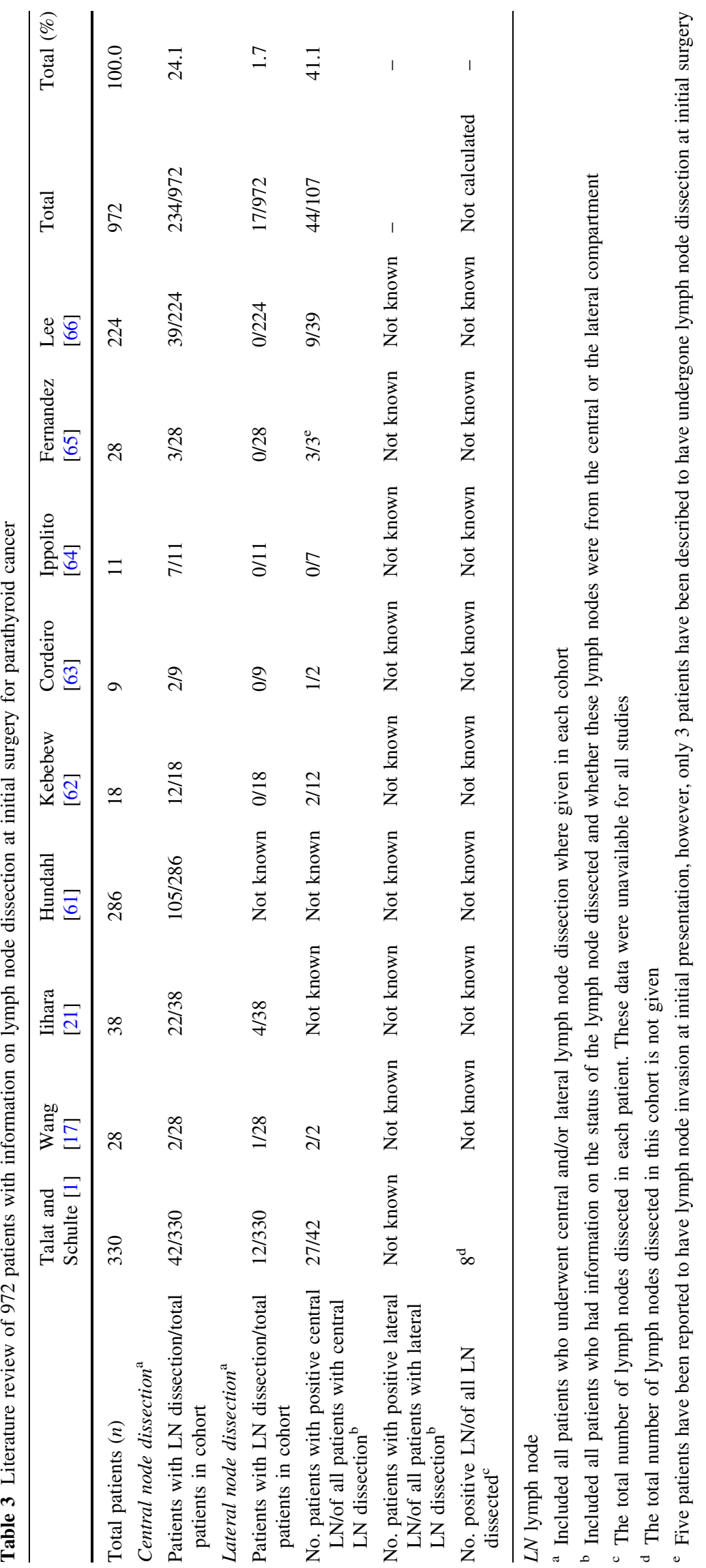




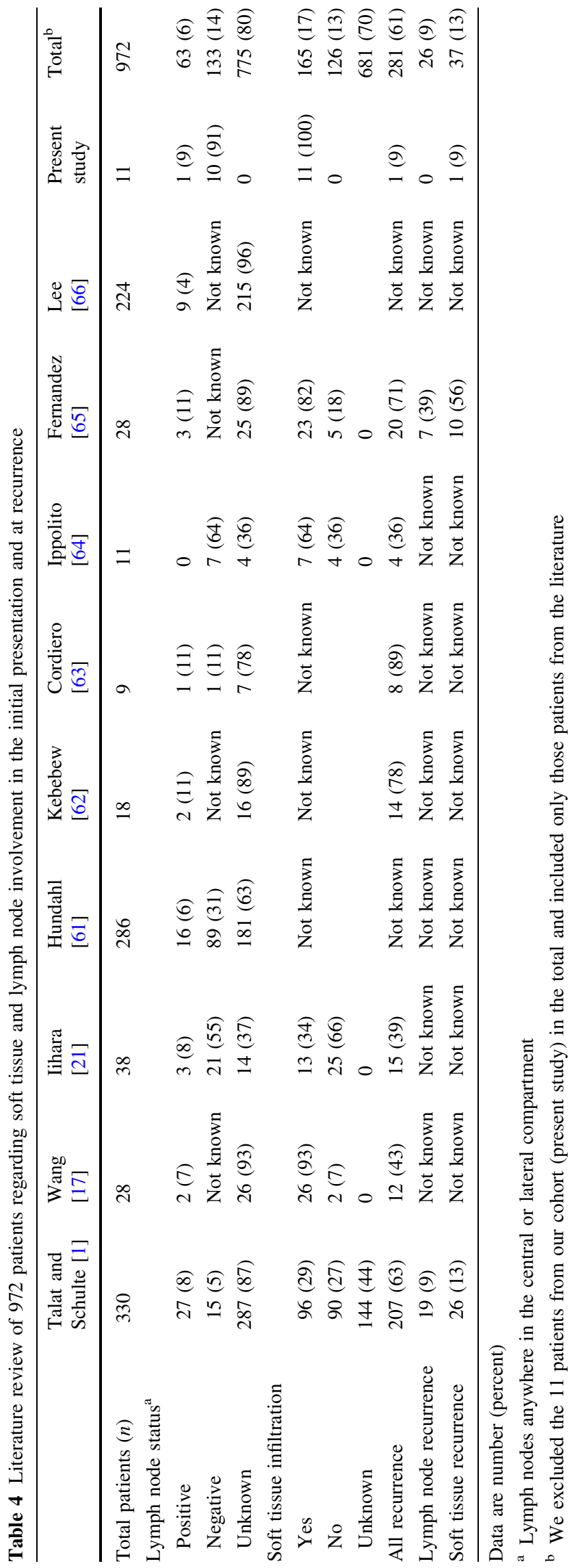

cancers presented as large-space-occupying lesions, eventually filling the entire central compartment. Completeness of central compartment resection is documented by strict adherence to anatomical landmarks and the inclusion of the thymus in the resection in these patients.

Recurrence was observed in only one patient (patient 2) resulting in a first redo surgery 13 months after initial surgery because of an increase in PTH with positive focal imaging on methionine PET [11]. The redo surgery comprised radical excision of two foci of local recurrence, including unilateral partial resection of the hypopharynx/ proximal oesophagus.

Adverse outcomes included two permanent recurrent nerve palsies resulting from nerve resection (patients 2 and 11) and one collection requiring interventional drainage after hypopharynx resection (patient 2).

Tables 3 and 4 present the data related to the extent and modality and related findings of lymph node resection and recurrence patterns. Some studies provided only partial information on some of these aspects. Given the scarcity of data in this field, we have chosen to present and exploit the exact information as indicated rather than to exclude these studies altogether. Figure 1 provides diagrammatic evidence of the low numbers of patients suitable for particular aspects of the analysis.

\section{Discussion}

Our series of 11 cases and the literature review of 972 patients present lymph node findings in parathyroid cancer. The diagnosis of parathyroid cancer in our 11 patients was solid, and we excluded patients in the literature who had an unclear diagnosis from assessment in this study.

Parathyroid cancer presents the clinician with three essential difficulties. The first problem is recognising the presence and extent of malignant parathyroid disease prior to surgery, i.e., a correct surgical staging. There are no reliable tools to help one recognise parathyroid cancer prior to surgery, and preoperative staging of lymph nodes has not been systematically described. Whilst extreme PTH and calcium levels can help give a first indication of malignancy, cancer may as well be present in less extreme metabolic situations $[49,59,69,70]$. In this study, the surgeon (KMS) departs from a high index of suspicion based on metabolic features such as high PTH and calcium, clinical features such as highly symptomatic pHPT or a palpable lesion, imaging findings on ultrasound, and the intraoperative finding of peritumoural inflammation or firm tumours. A combination of these criteria would then encourage a radical en bloc resection. All but two of the patients of this case series had en bloc surgery, including lymph node resection. 
Fig. 1 Graph showing the known site of locoregional recurrence in patients with parathyroid cancer. a The left diagram depicts the 330 patients from case reports for whom details of recurrence status are given. For those 45 patients in whom the site of recurrence can be safely identified, the right diagram identifies soft tissue versus lymph node recurrence. b The left diagram depicts the 132 patients from clustered data for whom details of recurrence status are given. For those 17 patients in whom the site of recurrence can be safely identified, the right diagram identifies soft tissue versus lymph node recurrence
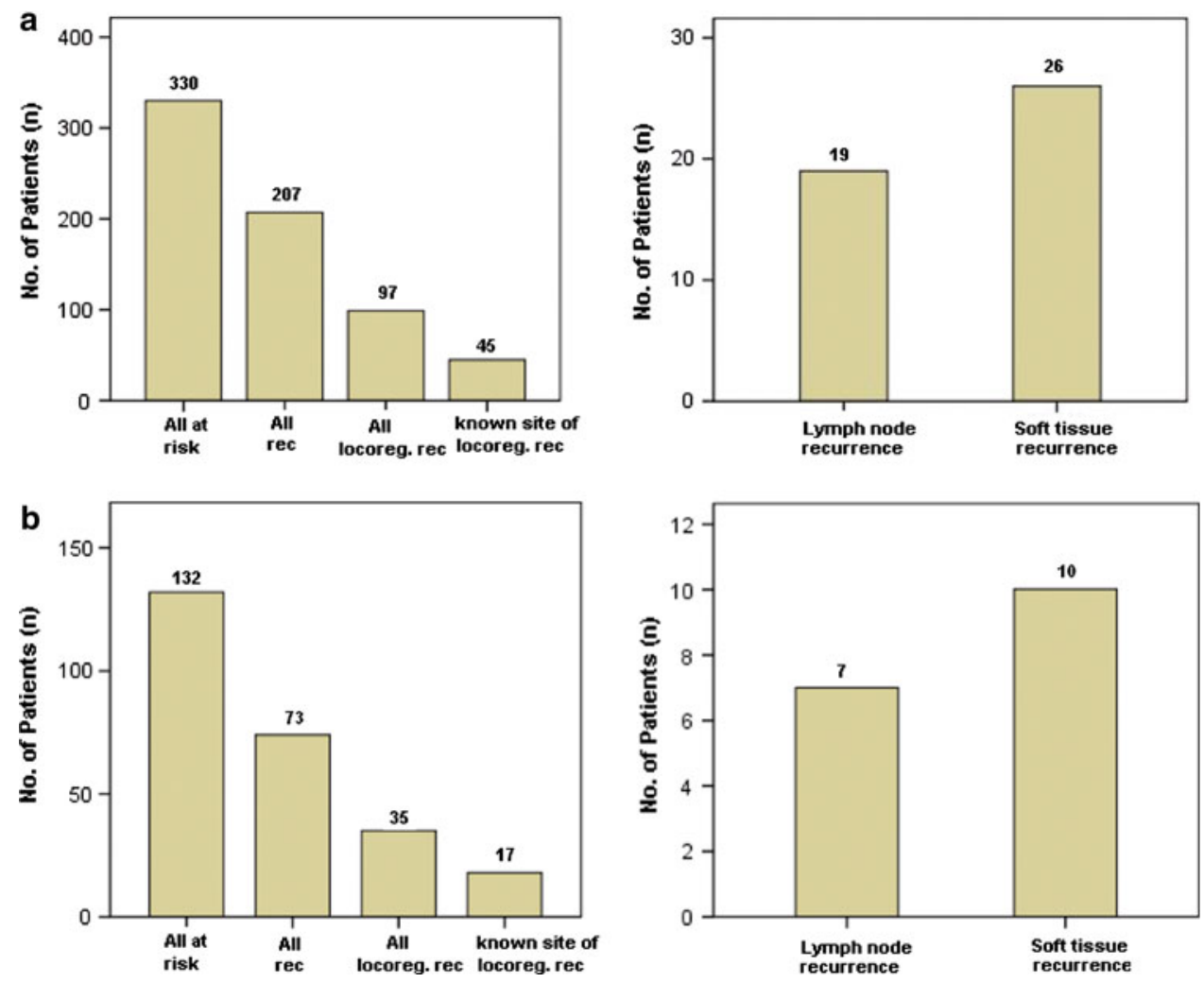

The second problem relates to the choice of the surgical approach. Even when cancer is diagnosed, there is no agreement on the extent of surgery to use beyond the acknowledgment that the tumour needs to be resected en bloc with all directly adherent tissues. In the absence of a pTNM staging system, the literature is difficult to interpret and short on comprehensive pathological staging information. As yet there is no useful information on the status of lymph node involvement.

The third problem relates to the high rate of locoregional recurrence and death in parathyroid cancer patients, even when an en bloc resection had been performed [1]. It is highly likely that a significant proportion of patients were understaged. It is not clear if locoregional recurrence originates mainly from primarily unresected lymph nodes, from direct cancer extension such as "tumour fingers," or from discontinuous extensions of the cancer into the soft tissue.

Hundahl [61] did not identify the effect of lymph node status on survival. His results may be limited by the small number of patients. In a recent comprehensive review of parathyroid cancer, the presence of lymph node metastases was significantly associated with a 6.2 -fold higher risk for death $(P<0.001)$ and an 8.5 -fold higher risk of locoregional recurrence $(P<0.001)$ [1]. The question therefore is whether locoregional recurrence and ultimately distant metastasis and death relate to a failure to resect the groups of primarily involved lymph nodes. Omission of lymph node resection as opposed to any form of systematic lymph node dissection involving the central and/or ipsilateral jugular compartment carried a 1.5-2-fold higher risk for recurrence and death at 5 years and overall [1], confirming earlier results by Koea [9].

The systematic evidence base of lymph node involvement in parathyroid cancer is sparse. This article contributes data on 11 patients with unequivocal parathyroid cancer who have undergone at least a systematic ipsilateral central lymphadenectomy. There were only two positive lymph nodes (from one patient) out of all 225 lymph nodes resected from our 11 patients (Table 2). Lateral lymphadenectomy did not identify any lymph node metastasis (Table 2). Table 3 compares the results of our small cohort with reports in the literature. Any form of central lymph node resection, i.e., not necessarily a resection of the entire central compartment, was performed in 234 of the 972 patients $(24.1 \%)$ reported on in the literature (Table 3). Of those 107 patients in the literature for whom the cancer status of these resected lymph nodes has been reported, there were $44(41.1 \%)$ with positive lymph node findings. The rates are quite dissimilar when the percentage of detected cancer-positive central lymph nodes is actually calculated as fraction of all patients reported in these studies: $11.1 \%$ [62], 11.1\% [63], 0\% [64], 17.9\% [65], $7.1 \%$ [17], 4.0\% [66], 9.1\% in our own series (Table 3).

The high percentage of positive lymph nodes anywhere in the central or lateral compartment, i.e., $63 / 196$ or $32.1 \%$ 
(Table 4), in those patients with reported status compared to the low number of patients with reported lymph node status, and the low percentage of $6.5 \%$ in the 972 patients in the literature with parathyroid cancer warns of the possibility of reporting biases for positive lymph node findings. The other underlying supposed bias likely is the careful pre- and intraoperative examinations that will have guided the surgical approach leading to an overrepresentation of positive lymph nodes in the resected group due to appropriate case selection.

Outside of our study, only 17 of the 972 patients $(1.7 \%)$ had undergone lateral neck dissection and the cancer findings in lymph nodes of these patients were not reported (Table 3). In addition, it is unclear what was the indication for central or lateral compartment resection in former cases and case series, adding another layer of likely bias toward overrepresentation of positive cases caused by an indication for lymph node removal based on pre- or intraoperative findings.

We conclude that central lymph node metastasis observed during the initial treatment of parathyroid cancer is reported in $0-17.9 \%$ of cases reported from cases series, in $8.1 \%$ of 330 individual case reports, and in $9.1 \%$ of the single systematically dissected case series presented here. Given the absence of alternative curative approaches, systematic dissection of the central lymph node compartment should be recommended as part of the initial surgery in all patients with suspected parathyroid cancer. It adds little if any morbidity to the procedure [71], even when performed as a secondary procedure [72]. There is not enough evidence to form a basis for early redo surgery for the sole purpose of lymph node clearance when a lesion was removed with free margins and was found to represent parathyroid cancer only by postoperative histology. The indication for a lateral compartment resection must be considered more critically. In our opinion there is clearly no indication for lateral neck dissection in parathyroid cancer in the absence of demonstrable suspicious or proven findings.

The observed pattern of lymphatic metastasis corresponds to former studies around the distribution of the parathyroid. Based on embryological and anatomical considerations, the lymphatic drainage should mostly comprise the central compartment but may directionally differ between upper and lower parathyroid glands. The orthotopic inferior parathyroid gland is located in the central compartment, mostly at either end or along the thyrothymic ligament [73, 74]. The lymphatic drainage field should hence correspond to the lower central compartment. However, it is well recognised that the lymphatic drainage of the key organ of the central compartment, i.e., the thyroid, is remarkably variable and may well lead into the lateral and mediastinal compartments in a significant number of patients [75]. This may explain the significant number of upper mediastinal recurrences in primarily en bloc resected parathyroid cancers [1]. The location of the orthotopic superior parathyroid gland varies considerably [73, 74]. Different from the inferior parathyroid gland, its blood supply is mostly from the superior thyroid artery [76]. Hence, its lymphatic drainage is ultimately related to the carotid artery and jugular vessels. This may explain the lateral lymph node findings in rare patients.

Given the relative rarity of documented lymph node metastasis either centrally or laterally, we still need to explain why lymphadenectomy on its own is a significant beneficial outcome predictor [1]. In the absence of sufficient data on lymph node status based on pathological examination of representative samples [1], the approach to the problem is under the caveat of possible significant interpretational errors. The most obvious confounder is the possibility that performance of a distinct form of lymph node dissection indicates a higher quality of surgery and possibly is directly linked with performance of a true en bloc resection with free margins. Lymph node involvement is observed in $32.1 \%$ of patients with known lymph node status, whilst soft tissue infiltration by the cancer has been reported in $56.7 \%$ of a sizable number of patients (Table 4). Invasion of surrounding tissues does not indicate a higher risk of locoregional recurrence, whilst vascular invasion carries a 4-fold higher risk of death or recurrence at 5 years and a 2.8- and 2.6-fold higher risk of overall recurrence and death, respectively [1]. Many recurrences will relate to distant metastases [1]. This leads us to the important question of whether lymph node metastasis is the determinant of locoregional recurrence. The site of locoregional recurrence is known for only $22.4 \%$ of the 281 reported patients with recurrence (Fig. 1; Table 4). Soft tissue recurrence accounts for $58.7 \%$ of these known sites, whilst recurrence in lymph nodes accounts for $41.3 \%$ (Table 4). Chest recurrence is frequent in parathyroid cancer [1]. Specifically in low-seated cancers there may be similarities with thyroid cancer, with discontinuous spread into the mediastinal compartment [77].

In summary, based on the scattered data of 983 patients (Table 4), soft tissue infiltration is more common than detected locoregional lymph node involvement at the time of initial surgery and soft tissue recurrence is more common than lymph node recurrence. Recurrence is a strong predictor of death in parathyroid cancer [1]. The risk of locoregional recurrence can be reduced by a combination of skeletonising anatomy-guided compartment resection without compromise at eventually compromised margins and systematic central lymphadenectomy. There is no indication for systematic lateral neck dissection. Depending on the location of the cancer, the upper mediastinum may be included in a radical approach. 


\section{Conclusion}

The evidence base for lymph node involvement by parathyroid cancer is sparse. The present study supports the view that central locoregional lymph node metastasis may initially be present in around $10 \%$ of patients and that the lateral compartment is rarely ever involved. Oncological en bloc clearance of the central compartment, including a systematic central lymph node resection, may improve outcomes and should be included in the routine approach to the suspicious parathyroid lesion. There is no need for a prophylactic lateral neck dissection.

\section{References}

1. Talat N, Schulte KM (2010) Clinical presentation, staging and long-term evolution of parathyroid cancer. Ann Surg Oncol 17:2156-2174

2. DeLellis RA, Mazzaglia P, Mangray S (2008) Primary hyperparathyroidism: a current perspective. Arch Pathol Lab Med 132(8):1251-1262

3. Wynne AG, van Heerden J, Carney JA et al (1992) Parathyroid carcinoma: clinical and pathologic features in 43 patients. Medicine (Baltimore) 71(4):197-205

4. Okamoto T, Iihara M, Obara T et al (2009) Parathyroid carcinoma: etiology, diagnosis, and treatment. World J Surg 33: 2343-2354

5. Holmes EC, Morton DL, Ketcham AS (1969) Parathyroid carcinoma: a collective review. Ann Surg 169(4):631-640

6. Clayman GL, Gonzalez HE, El-Naggar A et al (2004) Parathyroid carcinoma: evaluation and interdisciplinary management. Cancer 100(5):900-905

7. Obara T, Okamoto T, Kanbe M et al (1997) Functioning parathyroid carcinoma: clinicopathologic features and rational treatment. Semin Surg Oncol 13(2):134-141

8. Rao SR, Shaha AR, Singh B et al (2002) Management of cancer of the parathyroid. Acta Otolaryngol 122(4):448-452

9. Koea JB, Shaw JH (1999) Parathyroid cancer: biology and management. Surg Oncol 8(3):155-165

10. Rodgers SE, Perrier ND (2006) Parathyroid carcinoma. Curr Opin Oncol 18(1):16-22

11. Kulkarni PS, Parikh PM (2004) The carcinoma of parathyroid gland. Indian J Cancer 41(2):51-59

12. Fujimoto Y, Obara T (1987) How to recognize and treat parathyroid carcinoma. Surg Clin North Am 67(2):343-357

13. Shane E (2001) Parathyroid carcinoma. J Clin Endocrinol Metab 86(2):485-493

14. Aldinger KA, Hickey RC, Ibanez ML et al (1982) Parathyroid carcinoma: a clinical study of seven cases of functioning and two cases of nonfunctioning parathyroid cancer. Cancer 49(2):388-397

15. Obara T, Fujimoto Y (1991) Diagnosis and treatment of patients with parathyroid carcinoma: an update and review. World J Surg 15(6):738-744

16. Rawat N, Khetan N, Williams DW et al (2005) Parathyroid carcinoma. Br J Surg 92(11):1345-1353

17. Wang CA, Gaz RD (1985) Natural history of parathyroid carcinoma. Diagnosis, treatment, and results. Am J Surg 149(4): 522-527

18. Anderson BJ, Samaan NA, Vassilopoulou-Sellin R et al (1983) Parathyroid carcinoma: features and difficulties in diagnosis and management. Surgery 94(6):906-915
19. Sandelin K, Auer G, Bondeson L et al (1992) Prognostic factors in parathyroid cancer: a review of 95 cases. World J Surg 16(4):724-731

20. Levin KE, Galante M, Clark OH (1987) Parathyroid carcinoma versus parathyroid adenoma in patients with profound hypercalcemia. Surgery 101(6):649-660

21. Iihara M, Okamoto T, Suzuki R et al (2007) Functional parathyroid carcinoma: long-term treatment outcome and risk factor analysis. Surgery 142(6):936-943, discussion 943 e1

22. Cohn K, Silverman M, Corrado J et al (1985) Parathyroid carcinoma: the Lahey Clinic experience. Surgery 98(6):1095-1100

23. Jarman WT, Myers RT, Marshall RB (1978) Carcinoma of the parathyroid. Arch Surg 113(2):123-125

24. Fujimoto Y, Obara T, Ito $Y$ et al (1986) Localization and surgical resection of metastatic parathyroid carcinoma. World J Surg 10(4):539-547

25. Flye MW, Brennan MF (1981) Surgical resection of metastatic parathyroid carcinoma. Ann Surg 193(4):425-435

26. Masson EA, MacFarlane IA, Bodmer CW et al (1993) Parathyroid carcinoma presenting with a brown tumour of the mandible in a young man. Br J Oral Maxillofac Surg 31(2):117-119

27. Kirkby-Bott J, Lewis P, Harmer CL et al (2005) One stage treatment of parathyroid cancer. Eur J Surg Oncol 31(1):78-83

28. Cheah WK, Rauff A, Lee KO et al (2005) Parathyroid carcinoma: a case series. Ann Acad Med Singapore 34(7):443-446

29. Munson ND, Foote RL, Northcutt RC et al (2003) Parathyroid carcinoma: is there a role for adjuvant radiation therapy? Cancer 98(11):2378-2384

30. Chow E, Tsang RW, Brierley JD et al (1998) Parathyroid carcinoma-the Princess Margaret Hospital experience. Int $\mathrm{J}$ Radiat Oncol Biol Phys 41(3):569-572

31. Ou HY, Hung CJ, Hsu WH et al (2003) Variability of clinical presentations in three cases of parathyroid carcinoma. J Formos Med Assoc 102(4):266-269

32. Bhansali A, Kataria RN, Dutta P et al (2002) Parathyroid carcinoma: difficult management options. Indian J Cancer 39(3): $119-122$

33. Busaidy NL, Jimenez C, Habra MA et al (2004) Parathyroid carcinoma: a 22-year experience. Head Neck 26(8):716-726

34. Fujimoto Y, Obara T, Ito Y et al (1984) Surgical treatment of ten cases of parathyroid carcinoma: importance of an initial en bloc tumor resection. World J Surg 8(3):392-400

35. Kameyama K, DeLellis RA, Lloyd RV et al (2002) Parathyroid carcinomas: can clinical outcomes for parathyroid carcinomas be determined by histologic evaluation alone? Endocr Pathol 13(2):135-139

36. Aso Y, Sato A, Tayama K et al (1996) Parathyroid carcinoma with metastatic calcification identified by technetium- $99 \mathrm{~m}$ methylene diphosphonate scintigraphy. Intern Med 35(5):392395

37. McKeown PP, McGarity WC, Sewell CW (1984) Carcinoma of the parathyroid-gland-is it over-diagnosed?-a report of 3 cases. Am J Surg 147(2):292-298

38. Au WY (1975) Calcitonin treatment of hypercalcemia due to parathyroid carcinoma. Synergistic effect of prednisone on longterm treatment of hypercalcemia. Arch Intern Med 135(12): 1594-1597

39. Vetto JT, Brennan MF, Woodruf J et al (1993) Parathyroid carcinoma: diagnosis and clinical history. Surgery 114(5):882-892

40. Black BK (1954) Carcinoma of the parathyroid. Ann Surg 139(3):355-363

41. Saunders KB, Richardson J (1970) Carcinoma of the parathyroid. Proc R Soc Med 63(5):453-454

42. Sandelin K, Thompson NW, Bondeson L (1991) Metastatic parathyroid carcinoma: dilemmas in management. Surgery 110(6):978-986 discussion 986-988 
43. Barnes AD (1984) The changing face of parathyroid surgery. Ann R Coll Surg Engl 66(2):77-80

44. Ehrlich A, McDonald J, Zitani A Jr (1961) Carcinoma of the parathyroid with hyperparathyroidism and metastases. JAMA 176:453-455

45. de Papp AE, Kinder B, LiVolsi V et al (1994) Parathyroid carcinoma arising from parathyroid hyperplasia: autoinfarction following intravenous treatment with pamidronate. Am J Med 97(4):399-400

46. de la Garza S, de la Flores Garza E, Hernandez Batres F (1985) Functional parathyroid carcinoma cytology, histology, and ultrastructure of a case. Diagn Cytopathol 1(3):232-235

47. Solorzano CC, Carneiro-Pla DM, Lew JI et al (2007) Intraoperative parathyroid hormone monitoring in patients with parathyroid cancer. Ann Surg Oncol 14(11):3216-3222

48. Neumann DR, Esselstyn CB, Kim EY (1996) Recurrent postoperative parathyroid carcinoma: FDG-PET and sestamibi-SPECT findings. J Nucl Med 37(12):2000-2001

49. Dotzenrath C, Goretzki PE, Sarbia M et al (2001) Parathyroid carcinoma: problems in diagnosis and the need for radical surgery even in recurrent disease. Eur J Surg Oncol 27(4):383-389

50. Ito $\mathrm{Y}$, Iwase $\mathrm{H}$, Tanaka $\mathrm{H}$ et al (2001) Metachronous primary hyperparathyroidism due to a parathyroid adenoma and a subsequent carcinoma: report of a case. Surg Today 31(10):895-898

51. Obara T, Okamoto T, Ito Y et al (1993) Surgical and medical management of patients with pulmonary metastasis from parathyroid carcinoma. Surgery 114(6):1040-1048, discussion 1048-1049

52. Davies DR, Dent CE, Ives DR (1973) Successful removal of single metastasis in recurrent parathyroid carcinoma. Br Med J 1(5850):397-398

53. Weinstein RS (1991) Parathyroid carcinoma associated with polycythemia vera. Bone 12(4):237-239

54. Rufener JB, Cohen JI (2003) Metachronous spread of parathyroid carcinoma to a retropharyngeal lymph node. Head Neck 25(11):968-971

55. Pollack S, Goldin RR, Cohen M (1961) Parathyroid carcinoma. A report of two cases and a review of the literature. Arch Intern Med 108:583-587

56. Caley JP, Jones EE, Collins DH (1962) Fatal recurrence of parathyroid carcinoma after seven years. J Clin Pathol 15: 438-445

57. Placzkowski K, Christian R, Chen H (2007) Radioguided parathyroidectomy for recurrent parathyroid cancer. Clin Nucl Med 32(5):358-360

58. Qvist N, Krøll L, Ladefoged C et al (1986) Parathyroid carcinoma: a case with recurrence treated with extensive vascular surgery to the neck. Eur J Surg Oncol 12(2):187-191

59. Sheehan JJ, Hill AD, Walsh MF et al (2001) Parathyroid carcinoma: diagnosis and management. Eur J Surg Oncol 27(3):321324

60. Dubost C, Jehanno C, Lavergne A et al (1984) Successful resection of intrathoracic metastases from two patients with parathyroid carcinoma. World J Surg 8(4):547-551
61. Hundahl SA, Fleming ID, Fremgen AM et al (1999) Two hundred eighty-six cases of parathyroid carcinoma treated in the U.S. between 1985-1995: a National Cancer Data Base Report. The American College of Surgeons Commission on Cancer and the American Cancer Society. Cancer 86(3):538-544

62. Kebebew E, Arici C, Duh QY et al (2001) Localization and reoperation results for persistent and recurrent parathyroid carcinoma. Arch Surg 136(8):878-885

63. Cordeiro AC, Montenegro FL, Kulcsar MA et al (1998) Parathyroid carcinoma. Am J Surg 175(1):52-55

64. Ippolito G, Palazzo FF, Sebag F et al (2007) Intraoperative diagnosis and treatment of parathyroid cancer and atypical parathyroid adenoma. Br J Surg 94(5):566-570

65. Fernandez-Ranvier GG, Khanafshar E, Jensen K et al (2007) Parathyroid carcinoma, atypical parathyroid adenoma, or parathyromatosis? Cancer 110(2):255-264

66. Lee PK, Jarosek SL, Virnig BA et al (2007) Trends in the incidence and treatment of parathyroid cancer in the United States. Cancer 109(9):1736-1741

67. Agarwal G, Prasad KK, Kar DK et al (2006) Indian primary hyperparathyroidism patients with parathyroid carcinoma do not differ in clinicoinvestigative characteristics from those with benign parathyroid pathology. World J Surg 30(5):732-742

68. Robbins KT, Shaha AR, Medina JE et al (2008) Consensus statement on the classification and terminology of neck dissection. Arch Otolaryngol Head Neck Surg 134(5):536-538

69. Iacobone M, Lumachi F, Favia G (2004) Up-to-date on parathyroid carcinoma: analysis of an experience of 19 cases. J Surg Oncol 88(4):223-228

70. Robert JH, Trombetti A, Garcia A et al (2005) Primary hyperparathyroidism: can parathyroid carcinoma be anticipated on clinical and biochemical grounds? Report of nine cases and review of the literature. Ann Surg Oncol 12(7):526-532

71. Sadowski BM, Snyder SK, Lairmore TC (2009) Routine bilateral central lymph node clearance for papillary thyroid cancer. Surgery 146(4):696-703, discussion 703-705

72. Alvarado R, Sywak MS, Delbridge L et al (2009) Central lymph node dissection as a secondary procedure for papillary thyroid cancer: is there added morbidity? Surgery 145(5):514-518

73. Akerstrom G, Malmaeus J, Bergstrom R (1984) Surgical anatomy of human parathyroid glands. Surgery 95(1):14-21

74. Wang C (1976) The anatomic basis of parathyroid surgery. Ann Surg 183(3):271-275

75. Dixon E, McKinnon JG, Pasieka JL (2000) Feasibility of sentinel lymph node biopsy and lymphatic mapping in nodular thyroid neoplasms. World J Surg 24(11):1396-1401

76. Nobori M, Saiki S, Tanaka N et al (1994) Blood supply of the parathyroid gland from the superior thyroid artery. Surgery 115(4):417-423

77. Machens A, Holzhausen HJ, Dralle H (2004) Skip metastases in thyroid cancer leaping the central lymph node compartment. Arch Surg 139(1):43-45 